\title{
Conservación y protección de yacimientos arqueológicos del Bronce de La Mancha: propuesta metodológica
}

\section{Conservation and Preservation of Archaeological Sites from the Bronze Age in La Mancha: Methodological Proposal}

\author{
REBECA LENGUAZCO GONZÁLEZ \\ Universidad Autónoma de Madrid \\ rebecalenguazco@arkatros.com
}

\begin{abstract}
Resumen: Estudio de la conservación y preservación de los yacimientos pertenecientes a la denominada "facies motillas" del Complejo Cultural del Bronce de La Mancha, para lo cual ha sido necesaria la realización de un análisis exhaustivo que nos permitiera identificar el número de yacimientos constatados hasta la fecha, así como la valoración de su estado de investigación y conservación. Mediante la recopilación de los datos, obtenidos a partir de la consulta de las cartas arqueológicas, cartografía, fotografías aéreas, prospección y bibliografía, y su sistematización, abarcando aspectos como el estado actual de conservación, factores de alteración, dominio, protección patrimonial, clasificación del suelo, etc., se presenta un estado actual de la situación de los yacimientos al tiempo que se proponen las medidas correctoras convenientes que garantizarían su adecuada protección.
\end{abstract}

Palabras clave: Edad Bronce, conservación, preservación, metodología, Motilla.

\begin{abstract}
The study of the conservation and preservation of archaeological sites belonging to the so called "facies motillas" of the Bronze Cultural Complex of La Mancha, for which it was necessary to carry out an exhaustive analysis that would allow us to identify the number of sites found as to date, as well as the assessment of the state of research and conservation of them. Through the data collection, obtained from the archaeological charts, cartography, aerial photographs, prospecting and bibliography query, and their systematization, covering aspects such as the current state of conservation, alteration factors, domain, patrimonial protection, soil classification, etc., a current state of the deposits situation is presented while the convenient corrective measure is proposed that would guarantee their adequate protection.
\end{abstract}

Keywords: Bronze Age, Conservation, Preservation, Methodology, Motilla Site.

Recibido: 20 de noviembre de 2017; aceptado: 19 de mayo de 2018; publicado: 27 de septiembre de 2018. Revista Historia Autónoma, 13 (2018), pp. 31-54

DOI: https://doi.org/10.15366/rha2018.13.002 
Introducción

El patrimonio histórico según la Real Academia Española es el "conjunto de bienes de una nación acumulado a lo largo de los siglos, que, por su significado artístico, arqueológico, etc. son objeto de protección especial por la legislación". En este sentido, las motillas son yacimientos que forman parte del patrimonio arqueológico de Castilla-La Mancha, al mismo tiempo que son consideradas como asentamientos no solo emblemáticos de la Edad del Bronce en La Mancha sino también únicos en la Prehistoria peninsular. Este hecho las convierte, según la normativa vigente de patrimonio cultural de Castilla-La Mancha, en yacimientos susceptibles de recibir la máxima protección arqueológica por caracterizar la región.

Pero como de todos es sabido - usando el refranero español que bien define la situación"del dicho al hecho hay gran trecho", por lo cual se ha hecho una valoración global de la situación actual en la que se encuentran los yacimientos analizando su estado de investigación y de conservación, a fin de proponer medidas a adoptar que garanticen la correcta protección y preservación de los yacimientos, tanto sobre el terreno como administrativamente.

\section{1. ¿Cómo afrontar el problema y priorizar necesidades?}

Atendiendo a la cadena lógica de intervención en el patrimonio ${ }^{1}$ el presente trabajo sigue las siguientes fases:

1. Valoración del estado de la investigación. A partir de la recopilación de toda la documentación existente sobre los yacimientos objeto de estudio, junto con los resultados de los correspondientes trabajos de campo, se hace un diagnostico que nos permita valorar el estado actual de la investigación de las motillas.

2. Valoración del estado actual de conservación. Complementamos la documentación obtenida en la primera fase de estudio con datos relacionados con la situación administrativa, su estado visual de deterioro y los factores de alteración para, finalmente, hacer una valoración global de su estado de conservación. Ante la necesidad de sistematizar los datos para su posterior análisis e interpretación, se ha diseñado una ficha y un método de valoración del estado de conservación, adaptación del ya propuesto por los doctores Sánchez Meseguer y

\footnotetext{
${ }^{1}$ Bermúdez, Alejandro, et al., Intervención en el patrimonio cultural. Creación y gestión de proyectos, Madrid,
} Síntesis, 2004. 
Galán ${ }^{2}$ y del recientemente aplicado para valorar la oferta territorial de las motillas ${ }^{3}$, que supone la asignación de valores $(2,4,6,8,10 / 10)$ a cada uno de los "elementos" a contemplar y comprende los siguientes campos:

a) Datos de localización y situación administrativa (fig. 1): nombre del yacimiento (nomenclatura utilizada en la Carta Arqueológica o en su defecto, nombre más utilizado en caso de existir varias denominaciones para las localizaciones inéditas), código de carta arqueológica (número administrativo con el que está inventariado el yacimiento), número de yacimiento (número dado al yacimiento en catálogo confeccionado para el presente estudio), coordenadas UTM (X e Y del punto central del yacimiento en Datum ETRS89) y geográficas (latitud y longitud del punto central del yacimiento), provincia, municipio y comarca geográfica (donde se encuentra el yacimiento), clasificación del suelo (urbanizable o no urbanizable), dominio del suelo (público hidráulico o privado) y protección patrimonial (sin protección, Bien Inventariado o Bien de Interés Cultural).

Figura 1: Ficha datos de localización y situación administrativa.

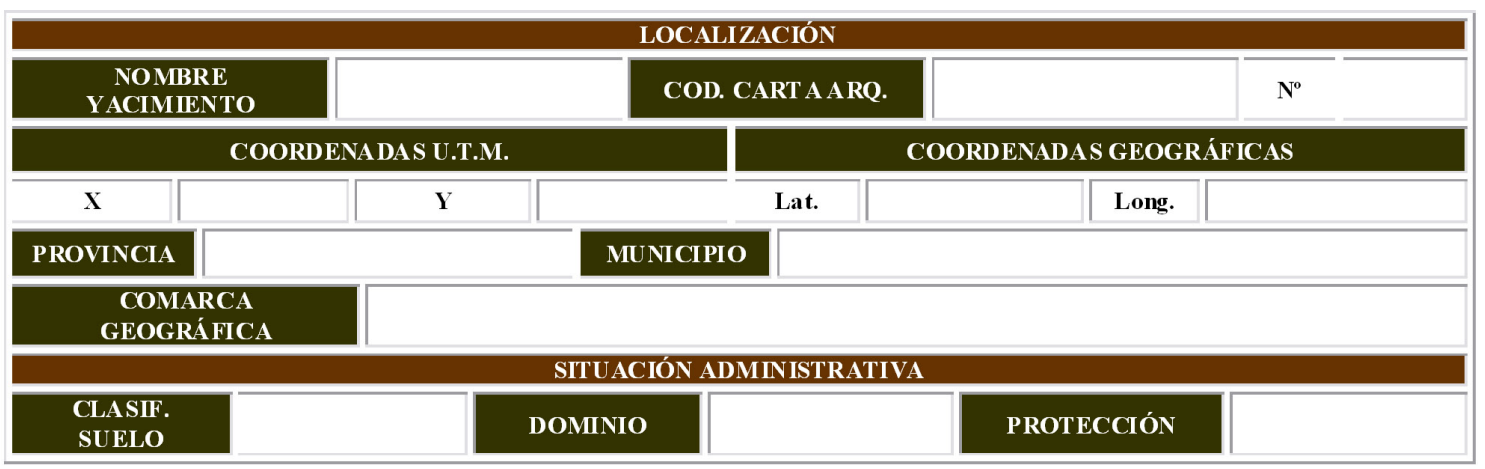

Fuente: Elaboración propia.

b) Valoración del estado actual de conservación (fig. 2): se divide en dos grandes bloques y una valoración global.

Bloque 1. Estados visibles de deterioro. En función del grado visible de afección se le asigna una calificación (valor): Consolidada (10), Parcialmente alterada (8) (aquellas en las que se aprecian fragmentos cerámicos en superficie, con escasas alteraciones y que por localizarse en terrenos inundables aparecen colmatadas, lo que podría favorecer su conservación), Alterada (6) (aquellas en las que se aprecian fragmentos cerámicos y conservan parcialmente la estructura "tumular" debido a diversas alteraciones), Muy

\footnotetext{
2 ${ }^{2}$ ánchez Meseguer, José Lorenzo y Catalina Galán Saulnier, “Arqueología e impacto ambiental: análisis del paisaje y medidas correctoras", en Cuadernos de Prehistoria y Arqueología de la Universidad Autónoma de Madrid, 27 (2001), pp. 125-151. DOI: http://dx.doi.org/10.15366/cupauam2001.27.007.

${ }^{3}$ Lenguazco González, Rebeca y Catalina Galán Saulnier, "Propuesta metodológica para la valoración de la oferta territorial en Arqueología Prehistórica: Las Motillas del Bronce de la Mancha", en Anejos a Cuadernos de Prehistoria y Arqueología de la Universidad Autónoma de Madrid, 2 (2016), pp. 107-116. DOI: http://dx.doi. org/10.15366/ane2.blasco2016.009.
} 
alterada (4) (aquellas en las que se aprecian fragmentos cerámicos en superficie y conservan una pequeña elevación sobre el terreno) y Desmantelada (2) (aquellas en las que no se conservan indicios del montículo y que, en el mejor de los casos, solo se aprecia algún fragmento cerámico).

Bloque 2. Factores de alteración: se analizan los factores naturales y biológicos, los antrópicos y la propia alteración según el uso histórico del suelo.

- Naturales y Biológicos. En función del grado de afección, salvo en las motillas desmanteladas o muy alteradas que el valor es " 0 ", se le asigna una calificación (valor): ninguna (10), ligera (8), media (6), fuerte (4) y muy fuerte (2).

- Antrópicos. Dividido a su vez en tres apartados:

Fases de reocupación, entendiendo que las fases de ocupación del mismo espacio afectan al estado de conservación de los restos de la Edad del Bronce se le asigna un número de épocas destacadas (valor): ninguna (10), una época destacada (8), dos épocas destacadas (6), tres épocas destacadas (4), más de tres épocas destacadas (2).

Intervenciones no arqueológicas, en función del grado de afección se le asigna una calificación (valor): ninguna (10), ligera (8), media (6), fuerte (4), muy fuerte (2).

Intervenciones arqueológicas, en función del tipo de intervención se le asigna un valor: excavación/consolidación (10), prospección (8), parcialmente excavada (4) y bastante excavada (2).

- Alteración según el uso histórico del suelo. Dividido a su vez en cuatro apartados que representan etapas cronológicas diferentes, a las que en función del grado de afección se le asigna una calificación (valor): no utilizado (10), ligeramente alterado (8), alterado (6), bastante alterado (4). Etapas cronológicas evaluadas:

Finales del siglo XIX, para cuya valoración se utilizan las hojas de la primera edición del MTN50 del área de estudio.

Primera mitad del siglo xx, para cuyo análisis se utilizan las fotos aéreas del vuelo fotogramétrico realizado en los años 1945-1946 (seria A) y 1956-1957 (serie B) por el Army Map Service de Estados Unidos y las hojas del MTN50 del área de estudio. Segunda mitad del siglo xx, para cuya valoración se utilizan las fotos aéreas del vuelo fotogramétrico interministerial (realizado entre 1973-1986) y del vuelo fotogramétrico nacional (entre 1980-1986).

Siglo xxI, para cuyo análisis se utilizan las fotos aéreas del vuelo fotogramétrico del Plan Nacional de Ortofotogrametría Aérea (PNOA) del año 2012 y las hojas del MTN50 del área de estudio.

Valoración global. Media de los valores asignados a los factores de alteración y al estado visible de deterioro: Muy Bien (100-91\%), Bien (90-71\%), Regular (70-51\%), Mal (50$31 \%$ ) y Muy Mal (inferior al 30\%). 
Figura 2: Ficha valoración del estado actual de conservación.

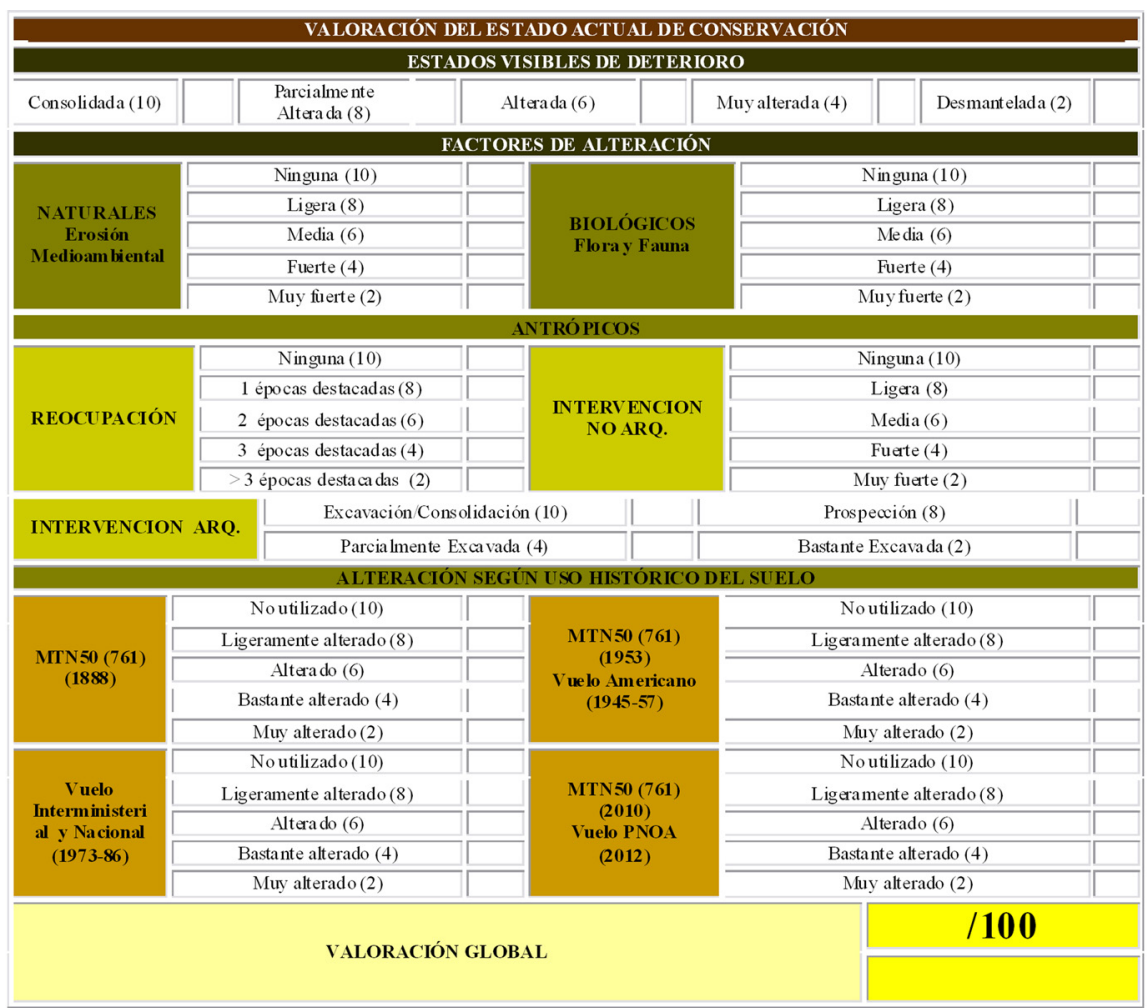

Fuente: Elaboración propia.

3. Propuestas de protección, conservación e intervención. Una vez analizado el estado de investigación, de conservación, los factores del deterioro y la protección patrimonial de las motillas estudiadas, se plantean propuestas de intervención que garanticen su correcta preservación y protección evitando así su constante degradación.

\section{Estado actual de la investigación}

La zona de estudio comprende el área central de la Comunidad de Castilla-La Mancha (actuales provincias de Albacete, Ciudad Real, Cuenca y Toledo), situada fundamentalmente en la submeseta sur de la Península Ibérica (fig. 3). La mayor parte de las motillas documentadas se localizan administrativamente en la provincia de Ciudad Real (35 yacimientos), con mayor concentración de yacimientos en los municipios de Daimiel (ocho motillas) y Alcázar de San Juan (siete motillas), lo que se corresponde con una ocupación mayoritaria de la comarca de llanura de La Mancha (33 motillas), en detrimento de las comarcas de transición del Campo de Calatrava, Campo de Montiel y Corredor de Almansa, con once yacimientos, o de las de 
sierra de los Montes de Toledo y Ciudad Real y las Sierras de Alcaraz y Segura (dos motillas), en función de la comarcalización geográfica de Castilla-La Mancha propuesta por Miguel Panadero y Félix Pillet ${ }^{4}$.

Figura 3: Localización geográfica de las motillas.

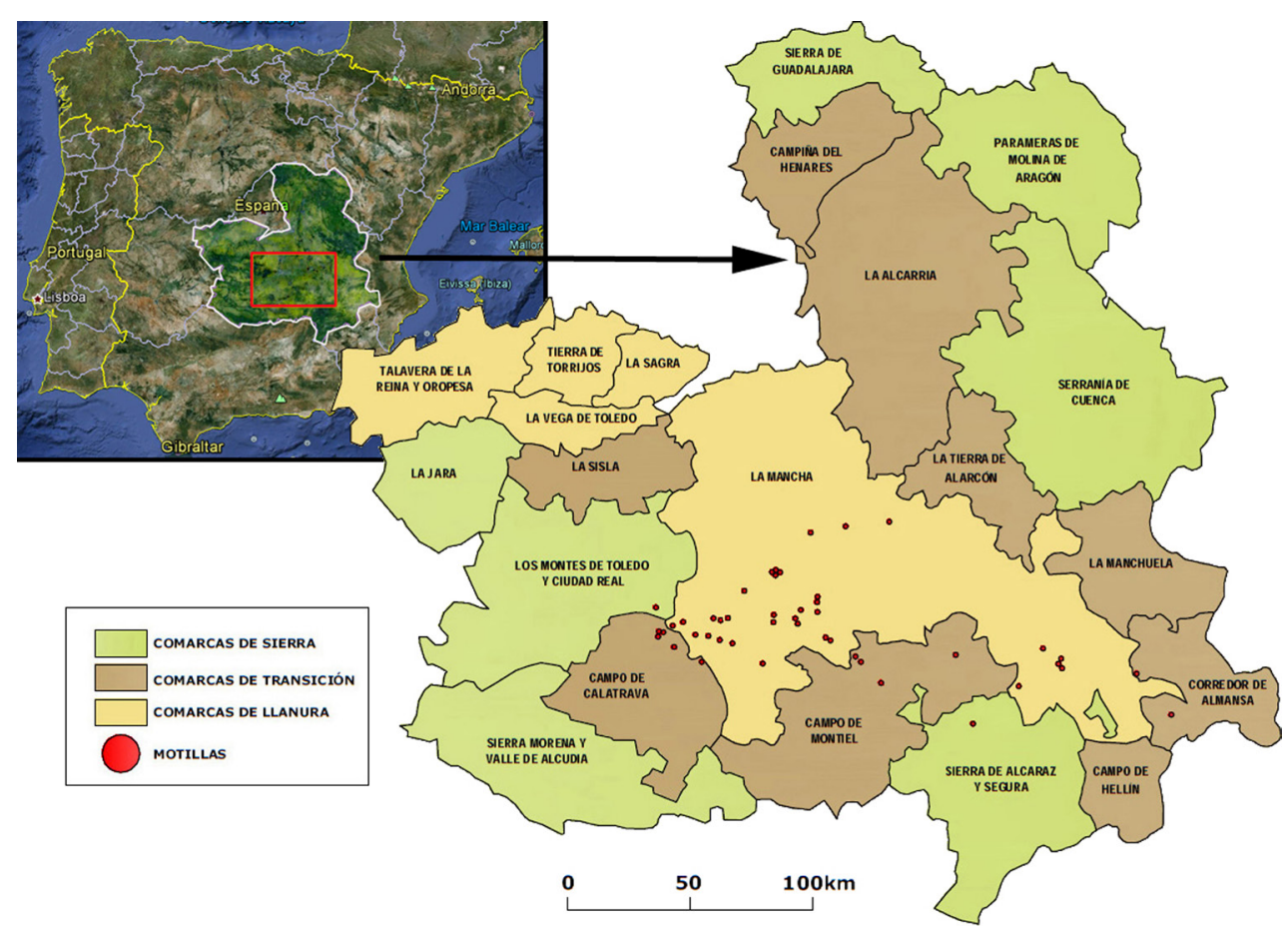

Fuente: Elaboración propia.

Hasta hace muy poco tiempo el número de motillas conocidas apenas sobrepasaba la treintena ${ }^{5}$, pero recientes estudios - algunos subvencionados por la Junta de Comunidades de Castilla-La Mancha ${ }^{6}$ y otros resultado de una reciente tesis doctoral ${ }^{7}$ - , han permitido ampliar ese número; así, pese a que recientemente aún algunos investigadores insisten en publicar la existencia de solo $32^{8}$, hoy podemos contemplar que con la reciente documentación de la

\footnotetext{
${ }^{4}$ Panadero Moya, Miguel y Félix Pillet Capdepon, "Las comarcas de la región”, en García Alvarado, José María y José Antonio Sotelo (eds.), La España de las autonomías, Madrid, Síntesis, 1999, pp. 291-330.

${ }^{5}$ Benítez de Lugo Enrich, Luis y Miguel Mejías Moreno, “Aspectos hidrogeológicos, paleoambientales, astronómicos y simbólicos del Bronce de La Mancha”, en Arqueología y Prehistoria del Interior Peninsular, 4 extra (2016), pp. 345-356. «http://www.arqueologiaprehistorica.es/arpi04.html» [consultado el 10 de noviembre de 2017].

${ }^{6}$ Proyecto de investigación "Ocupación del territorio y aprovechamiento de recursos en el Bronce de La Mancha: las motillas de la provincia de Ciudad Real y su territorio de explotación directa”, para el que se llevó a cabo una prospección arqueológica. Fue subvencionado por la Junta de Comunidades de Castilla-La Mancha (orden de convocatoria 12 de marzo de 2010) y dirigido por Dña. Rebeca Lenguazco González.

${ }^{7}$ Lenguazco González, Rebeca, Ocupación del territorio y aprovechamiento de recursos en el Bronce de La Mancha: las motillas y su territorio de explotación directa, Madrid, Arkatros, 2016. «https://repositorio.uam.es/ handle/10486/671726» [consultado el 10 de noviembre de 2017].

${ }^{8}$ Benítez de Lugo Enrich, Luis y Miguel Mejías Moreno, "The hydrogeological and paleoclimatic factors in Bronze Age Motillas Culture of La Mancha (Spain): the first hydraulic culture in Europe", en Hydrogeology Journal, 25 (2017). DOI: 10.1007/s10040-017-1607-z.
} 
Motilla de Mari López ${ }^{9}$ queda ampliado el número de yacimientos conocidos e identificados como motillas a 46 , localizados en:

Provincia de Ciudad Real:

1. Motilla de Los Romeros (Alcázar de San Juan)

2. Motilla de Pedro Alonso (Alcázar de San Juan)

3. Motilla de Casa de Mancha (Alcázar de San Juan)

4. Motilla de Brocheros (Alcázar de San Juan)

5. Motilla de Pedregosas (Alcázar de San Juan)

6. Motilla del Camino del Herradero I (Alcázar de San Juan)

7. Motilla del Camino del Herradero II (Alcázar de San Juan)

8. Motilla de Los Palacios (Almagro)

9. Motilla del Retamar (Argamasilla de Alba)

10. Motilla de Santa María (Argamasilla de Alba)

11. Motilla de Barrios (Argamasilla de Alba)

12. Motilla de Perales (Argamasilla de Alba)

13. Motilla de La Membrilleja (Argamasilla de Alba)

14. Motilla de Juez (Argamasilla de Alba y Alcázar de San Juan)

15. Motilla de El Cuervo (Campo de Criptana)

16. Motilla de La Huerta de Treviño (Campo de Criptana)

17. Motilla de Carrión (Carrión de Calatrava)

18. Motilla de El Azuer (Daimiel)

19. Motilla de La Vega Media (Daimiel)

20. Motilla de Daimiel (Daimiel)

21. Motilla de Zuacorta (Daimiel)

22. Motilla de La Máquina (Daimiel)

23. Motilla de La Albuera (Daimiel)

24. Motilla de Las Cañas (Daimiel)

25. Motilla del Cura (Daimiel)

26. Motilla del Quintillo (Fernán Caballero)

27. Motilla de Antonino (Fernán Caballero)

28. Motilla de Malagón (Malagón)

29. Motilla del Espino (Membrilla)

30. Motilla de La Cueva Morenilla (Ruidera)

31. Motilla de La Moraleja (Ruidera)

32. Motilla de Torralba (Torralba de Calatrava)

\footnotetext{
${ }^{9}$ Lenguazco González, Rebeca, "Poblamiento durante la Edad del Bronce en los Ojos del Guadiana: el yacimiento arqueológico de la Motilla de Mari López y su entorno", en Anejos a Cuadernos de Prehistoria y Arqueología de la Universidad Autónoma de Madrid, 3 (en prensa).
} 
33. Motilla de La Jacidra (Villahermosa)

34. Motilla de La Vega (Villarta de San Juan)

35. Motilla de Mari López (Villarrubia de Los Ojos)

Provincia de Toledo:

36. Motilla de El Morrión (E1 Toboso)

Provincia de Cuenca:

37. Motilla de El Pedernoso (El Pedernoso)

Provincia de Albacete:

38. Motilla de El Acequión (Albacete)

39. Motilla de Ojos de San Jorge (Albacete)

40. Motilla de Hoya Vacas (Albacete)

41. Motilla de Gorrineras (Albacete)

42. Motilla de Balazote (Balazote)

43. Motilla de Hoya Rasa (Corral Rubio)

44. Motilla de Prado Viejo (Hoya Gonzalo)

45. Motilla de Chavillo (Lezuza)

46. Motilla del Arquillo (Robledo)

Las motillas han sido objeto de interpretaciones muy diversas desde el siglo xv hasta la actualidad, pasando de ser consideradas meros accidentes geográficos desde finales del siglo XV hasta mediados del siglo XIX, a túmulos funerarios desde finales del siglo XIX e incluso estructuras palafíticas a mediados del siglo xx. Es a finales del siglo xx cuando comienzan las primeras excavaciones arqueológicas en algunas de las motillas (Los Romeros, El Azuer, Los Palacios, Las Cañas, Retamar y El Acequión), dando lugar a la formulación de distintas hipótesis. Fueron interpretadas por distintos equipos de investigación como construcciones defensivas, poblados fortificados de carácter agropecuario, asentamientos orientados al control de las vías de comunicación de uso ganadero y comercial e, incluso, caseríos y aldeas, sin hacer distinción entre morras y motillas ya que fueron consideradas como el mismo tipo de asentamiento $^{10}$. Ya en el siglo XXI se identifican como asentamientos en llano con fortificación central y localizados mayoritariamente en llanuras de inundación, tanto de ríos como de arroyos, seguidos en porcentaje por los que se encuentran en tablas fluviales, ojos y, en menor medida, por los emplazados en lagunas, con una importante función de gestión y control de recursos económicos, así como auténticos pozos fortificados ubicados donde el nivel freático se encuentra más próximo a la superficie ${ }^{11} \mathrm{o}$, incluso, localizados estratégicamente para el control

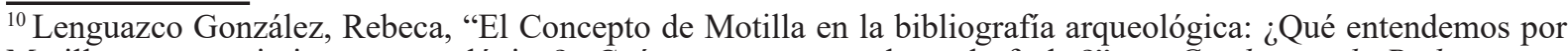
Motilla como yacimiento arqueológico? ¿Cuántas se conocen hasta la fecha?”, en Cuadernos de Prehistoria y Arqueología de la Universidad de Granada, 26 (2016), pp. 379-406.

${ }^{11}$ Nájera Colino, Trinidad y Fernando Molina González, "Las Motillas. Un modelo de asentamiento con fortificación central en la llanura de La Mancha", en García Huerta, Rosario y Francisco Javier Morales Hervás (coords.), La Península Ibérica en el II Milenio a. C. Poblados y fortificaciones, Cuenca, Ediciones de la Universidad
} 
de vados y vías naturales de comunicación, destacando su papel en relación con la trashumancia y los pastos de invierno ${ }^{12}$.

$\mathrm{Su}$ precario estado de investigación es debido a que la mayor parte de las motillas solamente han sido documentadas mediante prospección, no siempre sistemática, frente a una minoría que ha sido objeto de una investigación más exhaustiva. Este hecho no permite hacer extensivas a todas ellas ciertas características morfológicas y constructivas constatadas en el reducido número de casos en los que se han realizado excavaciones arqueológicas, máxime cuando esas mismas intervenciones han puesto de manifiesto la existencia de claras diferencias en este sentido. Por consiguiente, en el estado actual de la investigación, no se pueden valorar adecuadamente determinados aspectos como los relativos a las dimensiones de los respectivos asentamientos; el número de recintos de fortificación; la presencia/ausencia de torre central; la presencia/ausencia de pozo, solo constatado mediante excavación arqueológica en El Azuer, aunque algunos autores apuntan su posible existencia, a partir de estudios de prospección geofísica (tomografía eléctrica), perfiles de georradar y sondeos geotécnicos, en las motillas de La Vega Media ${ }^{13}$, El Acequión, Cura, Santa María y Retamar ${ }^{14}$; y la presencia/ausencia de poblado exterior (documentado mediante excavación arqueológica en El Azuer y Los Palacios).

A esta situación hay que sumarle los problemas derivados de su valoración cronocultural, ya que más de la mitad de los asentamientos han sido clasificados genéricamente como pertenecientes simplemente a la Edad del Bronce. En este sentido, en cuanto a la serie de dataciones radiocarbónicas (tabla 1) ${ }^{15}$ disponibles hasta la fecha, además de reducirse al 13\%

de Castilla-La Mancha, (2004), pp. 173-214; Benítez de Lugo Enrich, Luis y Miguel Mejías Moreno, "The hydrogeological..." op. cit.

${ }^{12}$ Ocaña Carretón, Andrés, "Las lagunas de Ruidera durante la Edad del Bronce: un Territorio Jerarquizado", en Trabajos de Prehistoria, 59 (2002), pp. 167-177. DOI: https://doi.org/10.3989/tp.2002.v59.i1.217; Lenguazco González, Rebeca, Ocupación del territorio... op. cit., pp. 197-210; Celis Pozuelo, Alberto, "Las vías pecuarias de Daimiel: caminos del pasado, caminos con futuro", en IV Jornadas de Historia de Daimiel (en prensa).

${ }^{13}$ Teixidó, Teresa et al., "Geoarchaeological Context of the Motilla de la Vega Site (Spain) Based on Electrical Resistivity Tomography", en Archaeological Prospection, 20 (2013), pp. 11-22. DOI: 10.1002/arp.1440.

${ }^{14}$ Mejías Moreno, Miguel et al., Arqueología, Hidrogeología y Medio Ambiente en la Edad del Bronce de La Mancha: la Cultura de las Motillas, Madrid, Instituto Geológico y Minero de España, 2015.

${ }^{15}$ Gorbea Almagro, Martín, El Bronce Final y el Periodo Orientalizante en Extremadura, Madrid Biblioteca Prehistórica Hispánica, 1977, p. 529; Alonso Mathias, Fernán et al., "Índice de fechas arqueológicas de C 14 en España y Portugal", en Almagro Gorbea, Martín y Manuel Fernández Miranda (eds.), C 14 y prehistoria de la Península Ibérica, Madrid, Fundación Juan March, 1978, pp. 155-183; Castro, Pedro et al., Cronología de la Prehistoria Reciente de la Península Ibérica y Baleares (c. 2800-900 cal ANE), Oxford. Oxford University Press, 1996; Evin, Jacques et al., "Lyon Natural radiocarbon measurements X", en Radiocarbon, 27 (1985), pp. 386454. DOI: 10.1017/S003382220000713X; Fernández-Posse, María Dolores et al., "Consideraciones cronológicas sobre la Edad del Bronce en La Mancha”, en Complutum, 6 extra (1996), pp. 111-138; Galán, Catalina y José Lorenzo Sánchez Meseguer, “Santa María del Retamar. 1984-1994”, en Sánchez Meseguer, Jose Lorenzo et al. (coords.), Jornadas de Arqueología de Ciudad Real en la Universidad Autónoma de Madrid. Patrimonio Histórico-Arqueología, Toledo, Junta de Comunidades de Castilla La Mancha, 1994, pp. 87-110; García Pérez, Tomás, "La Motilla de Los Romeros (Alcázar de San Juan, Ciudad Real)", en Oretum, 3 (1987), pp. 111-165; González, Cecilio et al., "University of Granada radiocarbon dates I", en Radiocarbon, 24 (1982), pp. $217-221$. DOI: 10.1017/S0033822200005063; González, Cecilio et al., "University of Granada radiocarbon dates II", en Radiocarbon, 27 (1985), pp. 610-615; González, Cecilio et al., "University of Granada radiocarbon dates III", en Radiocarbon, 28 (1986), pp. 1200-1205. DOI: 10.1017/S0033822200020208; González, Cecilio y Purificación Sánchez, "University of Granada radiocarbon dates V", en Radiocarbon, 33 (1991), pp. 367-373. DOI: 10.1017/ S0033822200040388; Lenguazco González, Rebeca, Estudio de materiales y análisis de su relación con los contextos excavados en la Motilla del Retamar, Madrid, Arqueoymás Monografías 3, 2012; Llorach, Rafael et al., Estudio de los restos vegetales arqueológicos del yacimiento "El Acequión”, Albacete (Edad del Bronce), Albacete, Instituto de Estudios Albacetenses, 2000; López Sáez, José Antonio et al., "Paleoambiente y sociedad en la Edad 
de las motillas, está compuesta por un número muy desigual de ítems (destacando la Motilla de El Azuer por su mayor número y por abarcar el lapso temporal más amplio) y son dataciones procedentes de diferentes tipos de muestras, realizadas por distintos laboratorios, que muestran importantes desviaciones, todo lo cual puede condicionar las valoraciones al efecto y dificultar la identificación no solo del comienzo del "fenómeno" de las motillas sino también del cese de su utilización. En consecuencia, no se puede establecer convenientemente — con suficientes argumentos contrastados - la correspondencia de todas o solo algunas a una o a varias etapas de ese periodo cultural, por lo que únicamente se puede afirmar actualmente que todas las motillas conocidas se utilizaron durante el Bronce Pleno (fig. 4).

Tabla 1. Dataciones radiocarbónicas de las motillas disponibles hasta la fecha.

\begin{tabular}{|c|c|c|c|c|c|c|c|}
\hline Yacimiento & Laboratorio & bp & \pm & cal+ & cal - & Muestra & Procedencia \\
\hline \multirow{3}{*}{ Los Romeros } & CSIC-78 & 3600 & 120 & 2160 & 1790 & $\begin{array}{l}\text { semillas- } \\
\text { cereal }\end{array}$ & $\begin{array}{c}\text { Fase } 1 . \\
\text { Nive19. Cereal } \\
\text { carbonizado de un } \\
\text { silo. }\end{array}$ \\
\hline & CSIC-76 & 3580 & 120 & 2130 & 1770 & carbón & $\begin{array}{c}\text { Fase 2. Nivel } 7 . \\
\text { Hogar. }\end{array}$ \\
\hline & CSIC-77 & 3290 & 120 & 1730 & 1450 & carbón & $\begin{array}{c}\text { Fase } 2 / 3.2^{\circ} \text { nivel } \\
\text { destrucción. Nivel } \\
\text { 6. Madera de } \\
\text { "Quercus". }\end{array}$ \\
\hline \multirow{2}{*}{ Retamar } & CSIC-796 & 3585 & 55 & 2037 & 1890 & carbón & $\begin{array}{c}\text { Corte "A". } \mathrm{Z}= \\
2,5-3,0 \mathrm{~m} .\end{array}$ \\
\hline & CSIC-797 & 3520 & 55 & 1934 & 1763 & carbón & $\begin{array}{c}\text { Corte "A". } \mathrm{Z}= \\
0,80 \mathrm{~m} .\end{array}$ \\
\hline \multirow{2}{*}{ Los Palacios } & UGRA-10 & 3580 & 150 & 2170 & 1740 & carbón & $\mathrm{Z}=-1,90 \mathrm{~m}$ \\
\hline & UGRA-110 & 3320 & 130 & 1760 & 1470 & carbón & \\
\hline Espino & GrN-8113 & 3420 & 120 & 1900 & 1580 & carbón & $\begin{array}{c}\text { Ladera este, } Z \\
=+2 \mathrm{~m} \text { sobre base. }\end{array}$ \\
\hline
\end{tabular}

del Bronce de La Mancha: La Motilla del Azuer", en Cuadernos de Prehistoria y Arqueología de la Universidad de Granada, 24 (2014), pp. 391-422; Martín Morales, Concepción, "Las fechas de Quintanar (Munera, Albacete) y la cronología absoluta de la Meseta sur", en Homenaje al profesor Martín Almagro Basch, Madrid, Ministerio de Cultura, 1983, pp. 23-35; Martín Morales, Concepción et al., "The Bronze Age of La Mancha", en Antiquity, 67 (1993), pp. 23-45 . DOI: http://dx.doi.org/10.1017/S0003598X00045038; Molina, Fernando y Trinidad Nájera, "Die Motillas von Azuer und Los Palacios (prov. Ciudad Real). Ein Beitrag zur Bronzezeit der Mancha", en Madrider Mitteilungen, 19 (1978), pp. 52-74; Molina, Fernando et al., "La Motilla del Azuer (Daimiel, Ciudad Real). Campaña de 1979", en Cuadernos Prehistoria y Arqueología de la Universidad Granada, 4 (1979), pp. 265294; Nájera, Trinidad y Fernando Molina, "La Edad del Bronce en la Mancha. Excavaciones en las Motillas del Azuer y Los Palacios (Campaña de 1974)", en Cuadernos Prehistoria y Arqueología de la Universidad Granada, 2 (1977), pp. 251-300; Nájera, Trinidad et al., "Un ejemplo de violencia interpersonal extrema durante la Edad del Bronce: el enterramiento 60 de La Motilla del Azuer", en Cuadernos Prehistoria y Arqueología de la Universidad Granada, 20 (2010), pp. 381-394; Nájera, Trinidad et al., "La población infantil de la Motilla del Azuer: un estudio bioarqueológico", en Complutum, 21 (2010), pp. 69-102. 
Rebeca Lenguazco González, "Conservación y protección de yacimientos...”

\begin{tabular}{|c|c|c|c|c|c|c|c|}
\hline Yacimiento & Laboratorio & bp & \pm & cal+ & cal - & Muestra & Procedencia \\
\hline \multirow{31}{*}{ El Azuer } & UGRA-129 & 3680 & 100 & 2230 & 1930 & semillas & Fase $1(-1,90 \mathrm{~m})$ \\
\hline & UGRA-127 & 3620 & 100 & 2160 & 1870 & semillas & Fase $1(-2,15 \mathrm{~m})$ \\
\hline & UGRA-20 & 3480 & 140 & 1990 & 1640 & carbón & $\begin{array}{c}\text { Fase 2. Final (- } \\
0,85 \mathrm{~m})\end{array}$ \\
\hline & Ly-2654 & 3530 & 130 & & & semillas & $\mathrm{Z}=-1 / 1,20 \mathrm{~m}$ \\
\hline & UGRA-114 & 3440 & 130 & 1936 & 1698 & semillas & $\mathrm{Z}=-1,1 \mathrm{~m}$. \\
\hline & UGRA-97 & 3490 & 180 & & & carbón & $\begin{array}{l}\text { Fase 2. Final } \\
(-4,05 \mathrm{~m})\end{array}$ \\
\hline & UGRA-19 & 3260 & 140 & 1750 & 1450 & carbón & Fase $5(-1,25 \mathrm{~m})$ \\
\hline & UGRA-21 & 3500 & 140 & 2030 & 1660 & carbón & Fase $2 / 3(-3,2 \mathrm{~m})$. \\
\hline & UGRA-118 & 3730 & 150 & 2451 & 1940 & semillas & Fase $1(-1,80 \mathrm{~m})$ \\
\hline & UGRA-132 & 4030 & 130 & 2760 & 2410 & carbón & Fase $1(-3,40 \mathrm{~m})$ \\
\hline & UGRA-145 & 3930 & 130 & 2600 & 2250 & carbón & $\mathrm{Z}=-2,40 \mathrm{~m}$ \\
\hline & UGRA-140 & 4000 & 140 & 2720 & 2340 & carbón & $\mathrm{Z}=-5,20 \mathrm{~m}$ \\
\hline & UGRA-115 & 3770 & 160 & & & carbón & $\mathrm{Z}=-1,05 \mathrm{~m}$ \\
\hline & UGRA-144 & 3840 & 120 & 2500 & 2140 & carbón & $Z=-5,70 \mathrm{~m}$ \\
\hline & Ly-2655 & 3540 & 130 & 2070 & 1720 & semillas & $\mathrm{Z}=-0,8 /-0,9 \mathrm{~m}$ \\
\hline & UGRA-109 & 3400 & 130 & 1890 & 1550 & carbón & $\begin{array}{l}\text { Fase 2. Final } \\
(-1,25 \mathrm{~m}) .\end{array}$ \\
\hline & Beta229993 & 3780 & 40 & 2342 & 2041 & hueso & Fase 1 \\
\hline & Beta325505 & 3670 & 30 & 2138 & 1957 & hueso & Fase 1 \\
\hline & Ua38423 & 3642 & 37 & 2135 & 1915 & carbón & Fase 2 \\
\hline & Ua38424 & 3630 & 35 & 2131 & 1895 & carbón & Fase 2 \\
\hline & Beta229995 & 3620 & 50 & 2139 & 1828 & hueso & Fase 2 \\
\hline & Ua38416 & 3591 & 37 & 2113 & 1782 & hueso & Fase 2 \\
\hline & Beta229994 & 3580 & 40 & 2034 & 1775 & hueso & Fase 2 \\
\hline & Ua38414 & 3498 & 38 & 1923 & 1697 & hueso & Fase 3 \\
\hline & Ua38411 & 3473 & 35 & 1888 & 1692 & hueso & Fase 3 \\
\hline & Beta230000 & 3450 & 40 & 1885 & 1667 & hueso & Fase 3 \\
\hline & Beta325506 & 3410 & 30 & 1866 & 1624 & carbón & Fase 3 \\
\hline & Beta230001 & 3330 & 40 & 1734 & 1515 & hueso & Fase 4 \\
\hline & Beta229992 & 3310 & 50 & 1735 & 1461 & hueso & Fase 4 \\
\hline & Ua38415 & 3172 & 36 & 1515 & 1392 & hueso & Fase 4 \\
\hline & Beta229999 & 3120 & 40 & 1494 & 1297 & hueso & Fase 4 \\
\hline
\end{tabular}




\begin{tabular}{|c|c|c|c|c|c|c|c|}
\hline Yacimiento & Laboratorio & bp & \pm & cal+ & cal - & Muestra & Procedencia \\
\hline \multirow{23}{*}{ El Acequión } & Beta 90883 & 3760 & 70 & 2400 & 1955 & carbón & $\begin{array}{l}\text { Fase } 1 . \text { Corte } 2 \\
(-5,12 \mathrm{~m}) .\end{array}$ \\
\hline & UGRA-304 & 3790 & 120 & 2470 & 2060 & carbón & \multirow{2}{*}{$\begin{array}{l}\text { Fase 2. Corte } 2 \\
(-2,58 \mathrm{~m}) .\end{array}$} \\
\hline & CSIC-832 & 3695 & 50 & 2198 & 2029 & carbón & \\
\hline & CSIC-829 & 3690 & 55 & 2197 & 2026 & carbón & $\begin{array}{l}\text { Fase 2. Corte } 5 \\
\qquad(-5,25 \mathrm{~m}) .\end{array}$ \\
\hline & CSIC-831 & 3610 & 65 & 2053 & 1896 & carbón & $\begin{array}{c}\text { Fase } 3 \mathrm{~A} . \text { Corte } 2 \\
(-1,97 \mathrm{~m}) .\end{array}$ \\
\hline & ICEN-50 & 3850 & 35 & 2456 & 2147 & \multirow{6}{*}{ carbón } & \multirow{6}{*}{$\begin{array}{c}\text { Fase } 3 \mathrm{~A} \text {. Corte } 7 \\
(-1,75 /-1,90 \mathrm{~m})\end{array}$} \\
\hline & UGRA-265 & 3770 & 80 & 2457 & 1942 & & \\
\hline & UGRA-271 & 3730 & 100 & 2457 & 1789 & & \\
\hline & UGRA-266 & 3680 & 80 & 2286 & 1784 & & \\
\hline & UBAR-50 & 3640 & 50 & 2138 & 1829 & & \\
\hline & CSIC-736 & 3600 & 50 & 2123 & 1775 & & \\
\hline & CSIC-828 & 3590 & 95 & 2194 & 1683 & \multirow[b]{2}{*}{ carbón } & \multirow{2}{*}{$\begin{array}{c}\text { Fase } 3 \mathrm{~B} \text {. Corte } 7 \\
(-1,5 \mathrm{~m}) .\end{array}$} \\
\hline & UGRA-309 & 3990 & 90 & 1425 & 926 & & \\
\hline & CSIC-830 & 3565 & 55 & 2034 & 1743 & \multirow{2}{*}{ carbón } & \multirow{2}{*}{$\begin{array}{c}\text { Fase } 3 \mathrm{~B} \text {. Corte } 2 \\
(-1,5 \mathrm{~m}) .\end{array}$} \\
\hline & UGRA-302 & 5010 & 150 & 4218 & 3385 & & \\
\hline & UGRA-307 & 3020 & 90 & 1420 & 1120 & & $\begin{array}{l}\text { Fase } 3 \mathrm{~B} \text {. Corte } 2 \\
\qquad(-0,3 \mathrm{~m}) .\end{array}$ \\
\hline & CSIC-827 & 3530 & 50 & 1937 & 1771 & carbón & $\begin{array}{l}\text { Fase } 3 \mathrm{~B} \text {. Corte } 1 \\
\qquad(-1 \mathrm{~m}) .\end{array}$ \\
\hline & $\begin{array}{c}\text { MAMS- } \\
17132\end{array}$ & 3708 & 25 & & & semilla & $\begin{array}{c}\text { AC.2A.88.14 } \\
(8 b) 461 / 89\end{array}$ \\
\hline & $\begin{array}{c}\text { MAMS- } \\
17128\end{array}$ & 3695 & 24 & & & hueso & $\mathrm{AC} / 6 / 87 / 61 / 1$ \\
\hline & $\begin{array}{c}\text { MAMS- } \\
17133\end{array}$ & 3685 & 25 & & & semilla & $\begin{array}{c}\text { AC. } 2 \text { A. } 88.12 \\
(25) 436 / 89\end{array}$ \\
\hline & $\begin{array}{c}\text { MAMS- } \\
17129\end{array}$ & 3677 & 25 & & & hueso & $\mathrm{AC} / 6 / 87 / 61 / 2$ \\
\hline & $\begin{array}{c}\text { MAMS- } \\
17127\end{array}$ & 3616 & 24 & & & hueso & $\mathrm{AC} / 18 / 87 / 10$ \\
\hline & MAMS- & 3494 & 24 & & & hueso & $\mathrm{AC} / 5 \mathrm{~A} / 87 / 1(2)$ \\
\hline
\end{tabular}

Fuente: Elaboración propia a partir de la bibliografía referenciada en la nota 15 y del visor IDEARQ, perteneciente al Consejo Superior de Investigaciones Científicas. 
Figura 4: Fases de ocupación de algunas motillas según las dataciones de C-14.

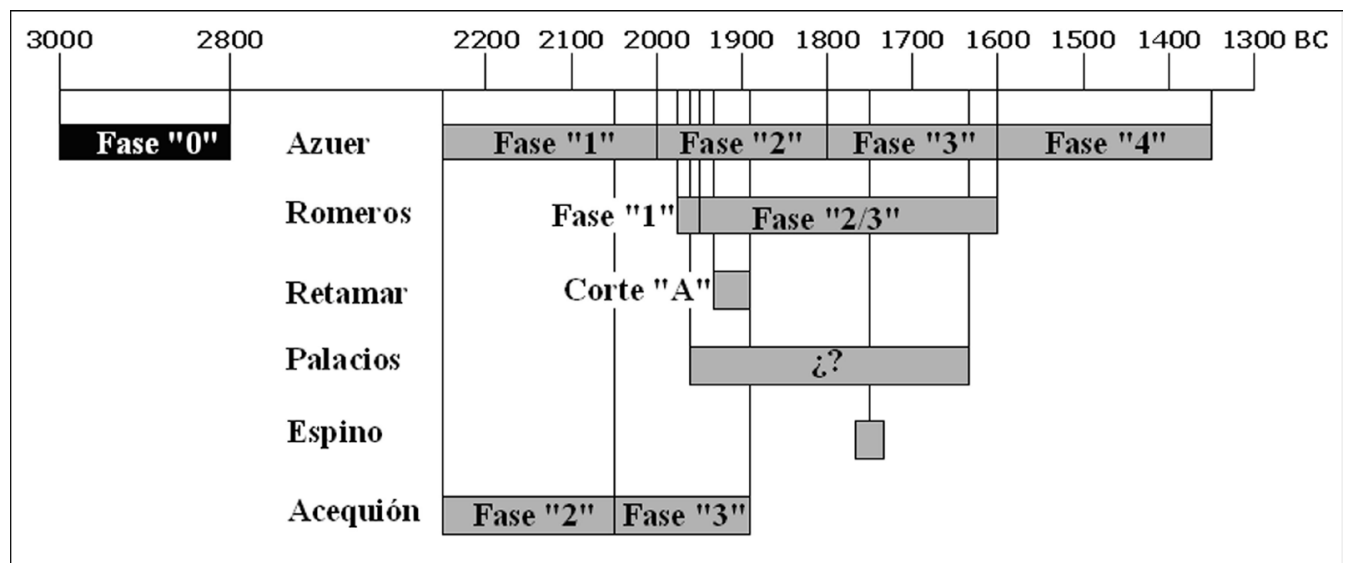

Fuente: Elaboración propia.

\section{Estado de conservación}

Desde el punto de vista administrativo, la mayor parte de los asentamientos se encuentran en suelos no urbanizables dedicados a la explotación agrícola intensiva, salvo la Motilla de Daimiel localizada en pleno casco urbano; igualmente, la mayoría es de dominio privado frente a una minoría que es de dominio público hidráulico (las motillas de Carrión, Las Cañas, Cura, Quintillo, La Cueva Morenilla y Hoya Rasa). Prevalecen las motillas protegidas patrimonialmente como Bien Inventariado frente a otras declaradas como Bien de Interés Cultural (El Azuer, Los Palacios y El Acequión) dentro de la categoría de zona arqueológica.

Son diversos los factores de deterioro que afectan al estado de conservación de los asentamientos, entre los que se encuentran:

a) Factores naturales: entre los procesos geomorfológicos postdeposicionales más destacados se encuentra la erosión, transporte y sedimentación provocada por distintos factores:

- Medioambientales: el propio clima, caracterizado en el área de estudio por su aridez y continentalidad, condiciona la rapidez de los procesos de alteración, fundamentalmente en aquellas motillas que presentan muros y cortes estratigráficos visibles. Entre los factores de alteración se encuentran:

La lluvia, que provoca erosión mecánica y deterioro por el estancamiento del agua en zonas que no pueden ser evacuadas, al tiempo que expone a los yacimientos a ciclos de hidratación-deshidratación que dan lugar a cambios en el volumen de las estructuras generando grietas que debilitan los muros, perfiles estratigráficos y áreas de excavación. 
Además, la intensidad de la lluvia provoca el desbordamiento de la escorrentía de agua superficial dando lugar al encharcamiento de los yacimientos, debido a su ubicación en entornos acuáticos, desplazando sedimentos y materiales arqueológicos e invadiendo las propias estructuras arqueológicas, siendo las más afectadas aquellas fabricadas con materiales arcillosos y con poca capacidad de drenaje. Sin embargo, el aumento de aridez ambiental da lugar a la evaporación del agua y con ello a procesos de salinización no solo de los materiales constructivos sino también del sustrato geológico, como consecuencia del descenso del nivel freático y desecación de las zonas encharcables, originando concreciones.

El viento, que favorece la erosión, el arrastre y la sedimentación superficiales.

Los cambios de temperatura, que originan contracciones y dilataciones que afectan a los materiales constructivos provocando cuarteamientos, agrietamientos y fracturas que condicionan la estabilidad estructural.

- Geomorfológicos y geotécnicos: tanto la pendiente como las capacidades de carga del terreno afectan directamente a las estructuras que empiezan a ceder, provocando hundimientos, agrietamientos, caídas parciales o desplomes de las mismas.

Desde el punto de vista geomorfológico ${ }^{16}$, la mayor parte de las motillas se encuentran en terrenos que presentan formas llanas con pendientes topográficas inferiores al 3\% y estabilidad natural elevada, excepto la Motilla de Las Cañas, localizada en las zonas pantanosas de Daimiel, y la Motilla de Hoya Rasa, emplazada en un territorio de morfología claramente irregular, con pendientes topográficas que oscilan entre 5 y $15 \%$, actualmente de estabilidad natural y artificial.

Desde el punto de vista de la geotecnia ${ }^{17}$, el $71 \%$ de los conjuntos arquitectónicos se levantaron en terrenos con una capacidad de carga alta o media, mientras que el $64 \%$ se construyeron en suelos de condiciones constructivas muy desfavorables o desfavorables. Entre los problemas constructivos se documentan los de tipo hidrológico y geotécnico mayoritariamente, pero también litológicos y geomorfológicos, según los baremos establecidos en función de las actuales condiciones ambientales.

- Gravedad: presenta una mayor influencia sobre las estructuras excavadas o cortes estratigráficos que conserven cierta altura, ya que acaban sufriendo desprendimientos.

b) Factores biológicos (fig. 5).

- Flora: la mayoría de las motillas presentan una cobertura vegetal compuesta fundamentalmente por plantas herbáceas y arbustivas, exceptuando El Azuer y los casos de yacimientos desmantelados, o incluso arbórea (motillas de El Acequión, Chavillo, Cura, La Cueva Morenilla, La Albuera, Quintillo y Espino) cuyas raíces provocan derrumbes, descohesión, movimientos, fisuras y fracturas.

\footnotetext{
${ }^{16}$ Lenguazco González, Rebeca, Ocupación del territorio... op. cit., p. 126.

${ }^{17}$ Ibídem, pp. 130-133.
} 
- Fauna: es frecuente localizar en los yacimientos múltiples madrigueras de pequeños mamíferos, sobre todo de liebres, conejos y roedores, así como perforaciones realizadas por lombrices de tierra y hormigas que acaban alterando estructuras murarias evidentemente en mayor medida los tapiales - y niveles arqueológicos.

Figura 5: Ejemplos de motillas con mayor exposición a factores naturales y biológicos de alteración.

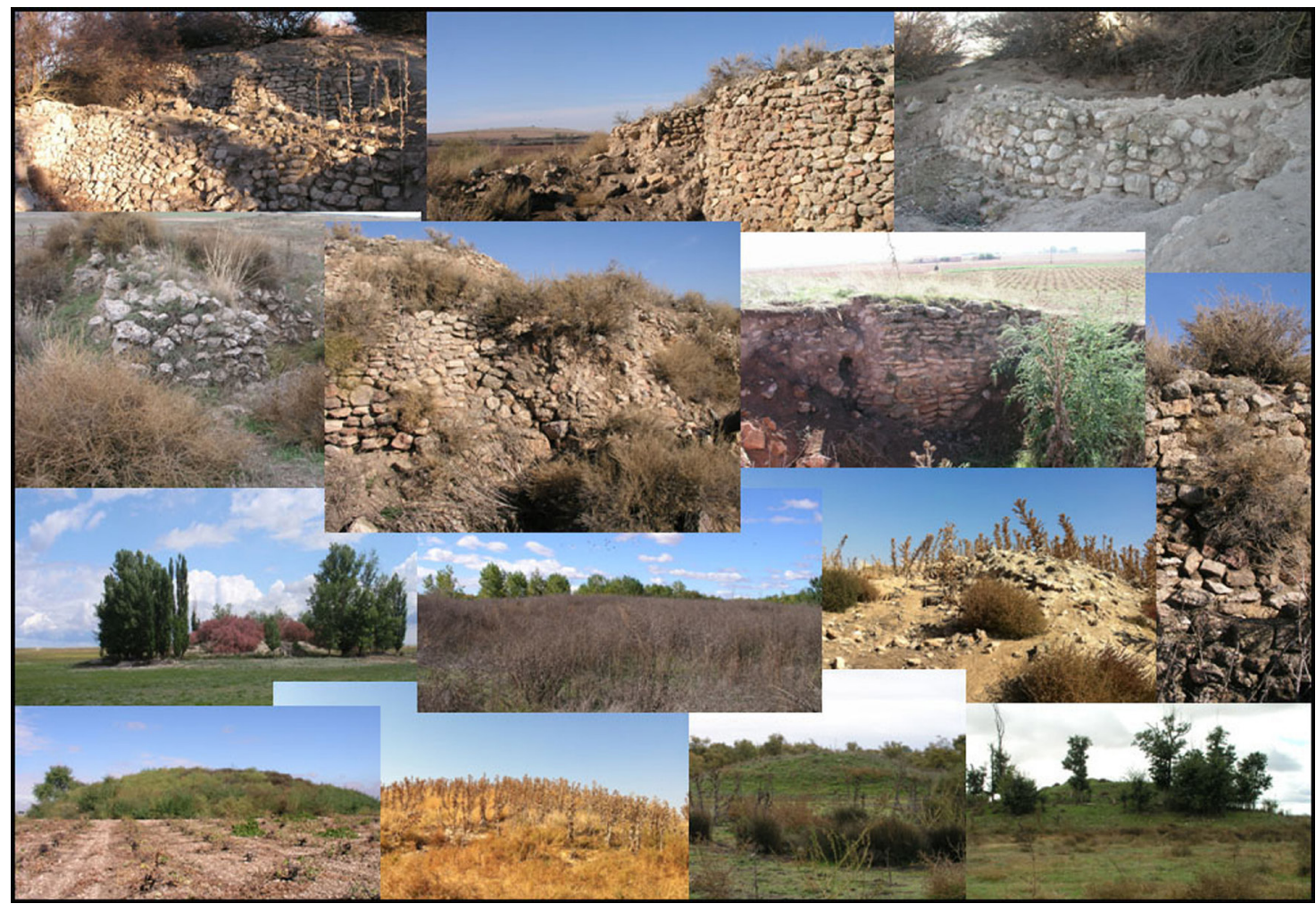

Fuente: Elaboración propia.

c) Factores antrópicos (fig. 6).

- Excavaciones arqueológicas: originan el debilitamiento de las estructuras arquitectónicas, que al ser exhumadas (motillas de Los Romeros, Los Palacios, Retamar, La Membrilleja, El Azuer, Las Cañas y El Acequión) acaban derrumbándose si no se consolidan —claro ejemplo de ello lo tenemos en el corte "A" de la Motilla del Retamar-, incluso puede producir la aparición de fisuras en las mamposterías debido a reajustes en las cargas de dichos volúmenes, como se detectó en la Motilla de El Azuer.

- Reocupación de las motillas: la reocupación de un mismo espacio en épocas distintas puede generar alteraciones tanto en las estructuras murarias como en la propia estratigrafía. En los casos estudiados, pertenecientes todos ellos a la Edad del Bronce, también se han detectado restos arqueológicos pertenecientes a la Edad del Hierro (motillas de Los 
Palacios, Retamar, La Huerta de Treviño, Las Cañas, Quintillo, Malagón, Espino, Morrión y El Acequión), a la época romana (motillas de Los Palacios, La Albuera, Quintillo, Malagón, Espino y El Acequión), a la época medieval (motillas de Pedregosas, Retamar, Los Palacios, Las Cañas, Quintillo, Antonino y Espino) y a las épocas moderna y contemporánea (motillas de La Huerta de Treviño, La Albuera, Quintillo, Juez, Malagón, Espino, La Membrilleja, Cuervo, La Vega, Daimiel, Mari López y Prado Viejo). Destacan los casos de la Motilla del Espino, sobre la que se construyó la Ermita de la Virgen del Espino, un mirador y se plantaron diversos árboles, y la Motilla de La Membrilleja, sobre la que se construyó el denominado Molino de la Membrilleja, actualmente desaparecido pero cuyas referencias figuran en las minutas cartográficas y en la primera edición de la hoja 739 del MTN50 (1886).

-Intervenciones no arqueológicas: provocan la destrucción parcial o total de estructuras murarias y niveles arqueológicos, afectando no solo a la interpretación del propio registro arqueológico sino también a la estabilidad del conjunto arquitectónico. Desgraciadamente, son diversos los casos documentados:

- Excavaciones ilícitas realizadas por aficionados, constatadas en las motillas de Los Romeros, Pedro Alonso, Brocheros, Guadiana, Las Cañas, Zuacorta, El Azuer, etc.

- Realización de obras públicas. Contamos con diversos casos como el de la Motilla de Zuacorta, que además de presentar un rehundimiento en su cima debido a una zanja excavada por furtivos también ha sido seccionada con otra gran zanja que atraviesa literalmente la motilla dañando la estabilidad del conjunto arquitectónico, relacionada con unas obras de canalización del Guadiana realizadas en la segunda mitad del siglo xx. En el caso de la Motilla de Los Palacios, además de presentar alteraciones debidas a una gran fosa de época moderna, también presenta un rebaje en su ladera sur objeto de la extracción de piedra para la construcción de una carretera cercana, hecho que también se constata en la Motilla del Retamar. Por otro lado, cabría destacar la Motilla de La Moraleja, que ha sido atravesada por la construcción de un camino que cruza el río Guadiana y la Motilla de Balazote, destruida al construir la carretera que une Balazote con la general Albacete-Jaén.

- Desarrollo urbanístico. La Motilla de Daimiel se encuentra desmantelada en la actualidad tras la construcción del Centro Cultural La Motilla en Daimiel.

- Construcción de hornos de cal o caleras. Las motillas de Malagón, Juez y Mari López se encuentran actualmente desmanteladas por reutilizarse sus materiales constructivos - piedra caliza - tanto para la extracción de cal como para la construcción de los hornos, tradicionalmente utilizados hasta finales del siglo xx.

- Actividad agropecuaria. La actividad ganadera genera efectos de compactación, erosión y destrucción de estructuras debido al efecto que produce la acción 
mecánica de las pezuñas, pero ha sido sobre todo el desarrollo de la agricultura moderna lo que ha provocado el mayor impacto sobre la integridad de los asentamientos ${ }^{18}$. En este sentido, destaca fundamentalmente la destrucción de las motillas de La Jacidra, a finales del siglo Xx, y La Máquina ${ }^{19}$, a principios del siglo XXI, hechos que quedaron impunes a pesar de contar ya con una "legislación sectorial específica para proteger el Patrimonio Histórico" ${ }^{20}$.

Figura 6: Ejemplos de factores antrópicos de alteración.

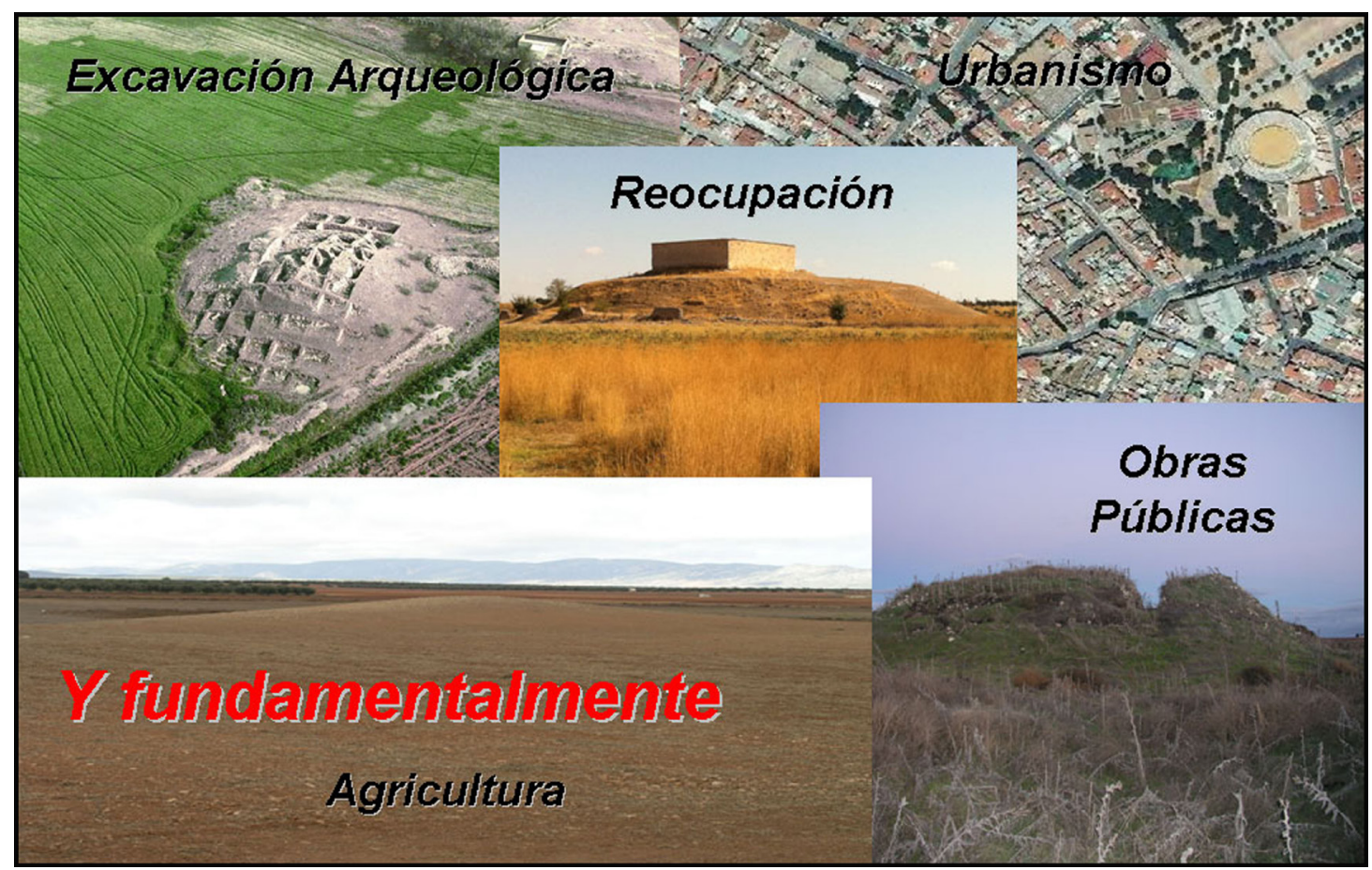

Fuente: Elaboración propia.

Aunque no se aprecien estructuras emergentes, en la actualidad pueden conservarse en relación con niveles arqueológicos en el subsuelo. Asimismo, la particular ubicación de las motillas, asociada en la mayoría de los casos a cauces fluviales, podría haber dado lugar a la formación de niveles de colmatación con sedimentos, al menos en los niveles inferiores de las fortificaciones y, en su caso, de los poblados circundantes, lo que presumiblemente podría haber contribuido a garantizar su conservación, si no total, al menos sí parcialmente.

\footnotetext{
${ }^{18}$ Jiménez Ramírez, Salvador y Antonio Chaparro Sabina (eds.), Las Lagunas de Ruidera en el tiempo, Ciudad Real, edición de los autores, 1989; Ocaña Carretón, Andrés, "El impacto de la agricultura moderna sobre la conservación del Patrimonio Arqueológico en la Llanura Manchega: el caso de las Motillas", en Zarzalejos Prieto, Mar et al. (coords.), Actas del I Congreso de Patrimonio Histórico de Castilla La Mancha. Vol. 2, Valdepeñas, Universidad Nacional de Educación a Distancia, 2007, pp. 399-409.

${ }^{19}$ Benítez de Lugo, Luis, Las Motillas y el Bronce de La Mancha, Ciudad Real, Anthropos, 2010.

${ }^{20}$ Benítez de Lugo, Luis, "Las motillas en el entorno de Daimiel. Investigación histórica y gestión del Patrimonio Cultural", en II Jornadas de historia de Daimiel: 125 aniversario ciudad de Daimiel, Daimiel, Ayuntamiento de Daimiel, 2013, p. 39.
} 
El propio uso de la toponimia ${ }^{21}$, de las minutas cartográficas $\mathrm{y}$, sobre todo, de las fotografías aéreas antiguas ha permitido recientemente constatar la ubicación y dimensiones aproximadas de buena parte de los asentamientos estudiados, actualmente desmantelados total o parcialmente, cuyo único indicio en superficie es una pequeña concentración de material arqueológico asociado, en el mejor de los casos, a una suave elevación del terreno. Destaca el caso de la Motilla de Barrios, donde el topónimo "motilla", ya desaparecido en cartografía reciente, figuraba asociado al asentamiento en las minutas cartográficas, al mismo tiempo que la consulta de las fotografías aéreas ha permitido valorar sus dimensiones antes del desmantelamiento (fig. 7), así como La Albuera (actualmente imperceptible en prospección pero cuya existencia ha podido ser constatada gracias a la consulta de las fotografías aéreas) y Camino del Herradero I y II ${ }^{22}$, descubiertas durante trabajos de prospección, en los que tanto la consulta de la toponimia asociada - El vado de los hitos - como de la fotografía aérea ha permitido verificar la existencia de estos yacimientos.

Figura 7. Cambios de visibilidad en fotografía aérea de la estructura tumular de las motillas de Barrios y La Albuera según el uso histórico del suelo.

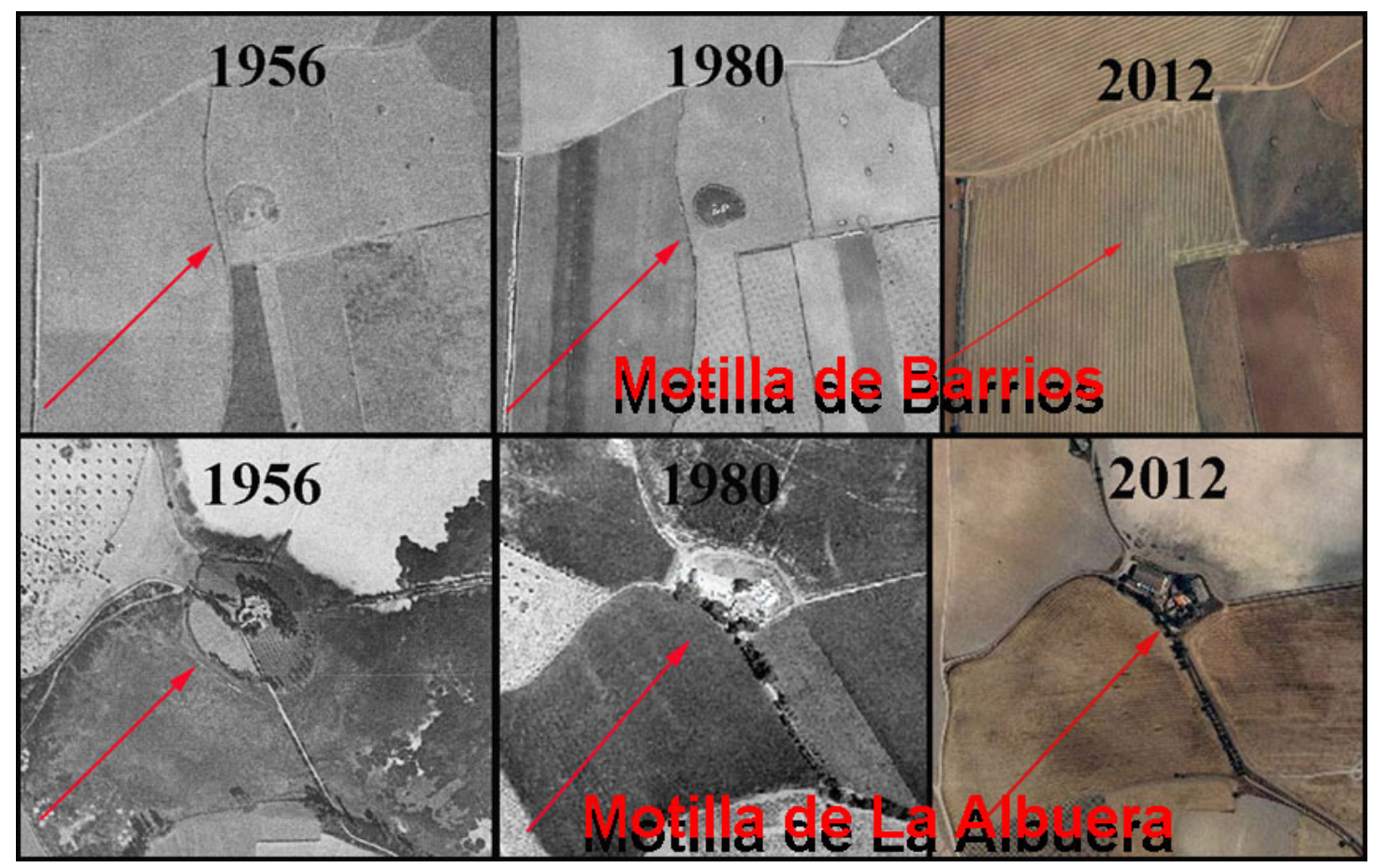

Fuente: Vuelo fotogramétrico de 1956 (serie B) realizado por el Army Map Service de Estados Unidos, vuelo fotogramétrico interministerial y Nacional de 1980 y vuelo fotogramétrico del Plan Nacional de Ortofotogrametría Aérea (PNOA) del año 2012.

\footnotetext{
${ }^{21}$ Lenguazco González, Rebeca, "El uso de la toponimia para la identificación de yacimientos arqueológicos y sus territorios de explotación directa: el caso particular de las Motillas", en Catastro, 88 (2016), pp. 73-104. «https:// issuu.com/catastro_digital/docs/catastro_88/85» [consultado el 11 de noviembre de 2017].

${ }^{22}$ Lenguazco González, Rebeca, Ocupación del territorio.... op. cit., p. 161.
} 
También se han detectado ciertos indicios de la existencia de evidencias arqueológicas, consistentes en cambios de coloración en el terreno ${ }^{23}$, que podrían corresponder a la ubicación de posibles poblados situados alrededor de los montículos artificiales en las motillas de Los Romeros, Pedro Alonso, Brocheros, Vega Media, Torralba y Morrión. Estos datos fueron constatados posteriormente durante prospección superficial con el hallazgo de materiales arqueológicos asociados a dichos cambios de coloración (fig. 8). En cualquier caso, hay que contemplar la posibilidad de que la existencia de un posible poblado exterior no sea fácilmente detectable ni en las fotografías aéreas ni en el transcurso de una prospección superficial en todos los casos. Ejemplo de ello es la Motilla de Los Palacios donde, a pesar de no apreciarse dichos indicios en fotografía aérea, se constató arqueológicamente la existencia de un poblado exterior alrededor de la fortificación; apreciación que, en el caso de la de El Azuer, sí fue contrastada con la fotografía aérea del vuelo americano serie $\mathrm{B}$, que mostraba una clara diferenciación en la coloración del terreno alrededor del montículo y, posteriormente, las excavaciones arqueológicas han corroborado ${ }^{24}$.

Figura 8: Diferenciación de coloración del terreno alrededor de las motillas de Los Romeros, Pedro Alonso y El Morrión que podría corresponderse con la existencia de un poblado alrededor de la fortificación.

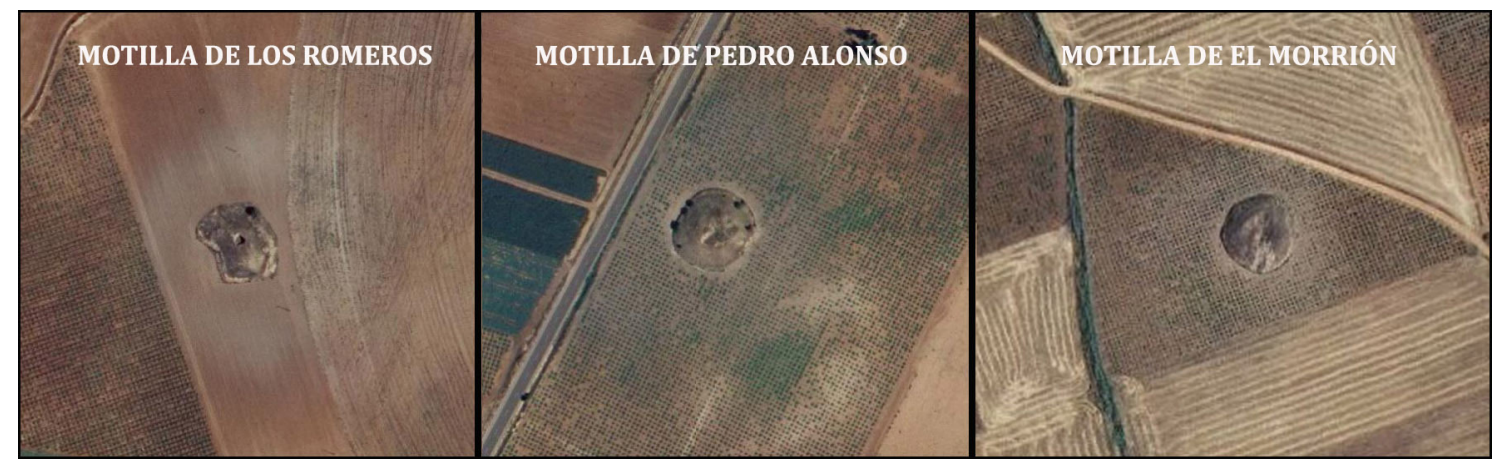

Fuente: Vuelo fotogramétrico del Plan Nacional de Ortofotogrametría Aérea (PNOA) del año 2012.

Asimismo, el estudio de la fotografía aérea ha permitido detectar ciertos rasgos morfológicos como la existencia de varios lienzos concéntricos de amurallamiento o, incluso, lo que podría corresponderse con una torre central en algunos de los asentamientos estudiados (motillas de Carrión, Cura y Quintillo), datos que han sido corroborados durante trabajos de prospección (fig. 9).

\footnotetext{
${ }^{23}$ Ibídem, p. 162.

${ }^{24}$ Nájera Colino, Trinidad y Fernando Molina González, “La Edad del Bronce...” op. cit., pp. 251-300.
} 
Figura 9: Diferenciación de ciertos rasgos morfológicos como líneas de amurallamiento o posible torre central en las motillas de Carrión, Quintillo y Casa del Cura.

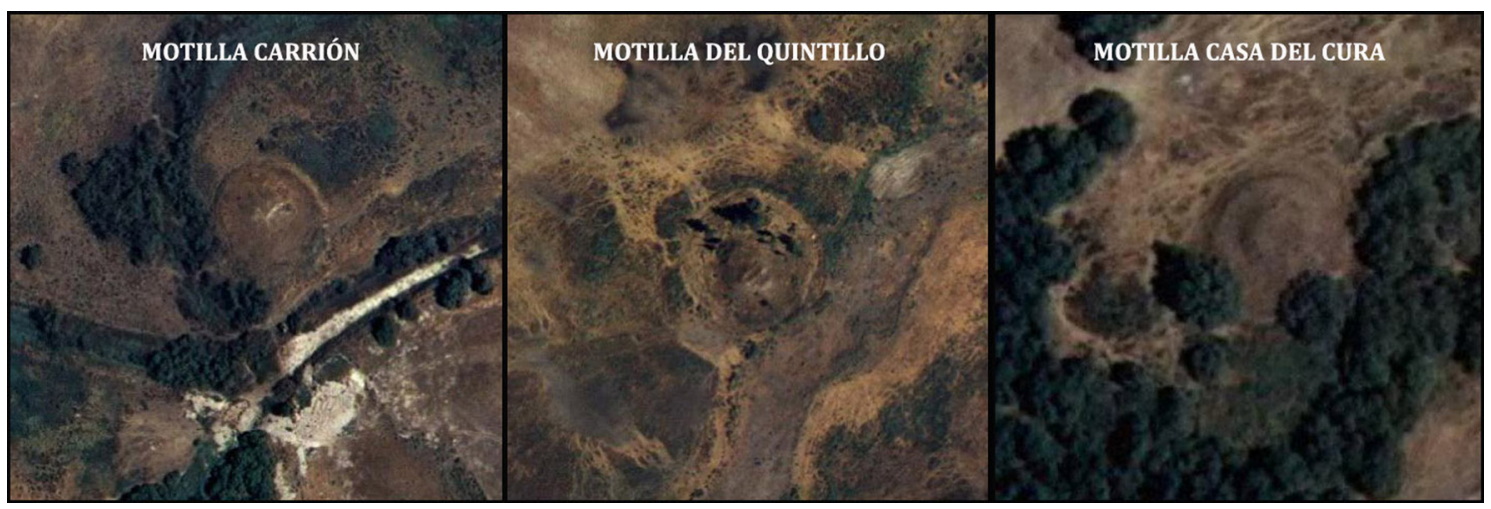

Fuente: Vuelo fotogramétrico del Plan Nacional de Ortofotogrametría Aérea (PNOA) del año 2012.

Aunque todas las motillas presentan un estado de abandono que favorece su constante degradación, exceptuando el Azuer (la única que ha sido restaurada y consolidada y en la que se desarrollan labores de acondicionamiento, limpieza y mantenimiento), se aprecian distintos estados de conservación según la valoración global, clasificándose la mayoría (39\%) como Regular, seguidamente las definidas como Bien (24\%), mientras que el $20 \%$ figuran como Muy mal y, por último, Mal el $15 \%$ de los asentamientos.

\section{Propuestas de protección y conservación}

Una vez analizado el estado de investigación y de conservación de los distintos asentamientos, ya que "los proyectos de consolidación, restauración y puesta en valor deben estar basados en los sólidos conocimientos aportados por los proyectos de investigación, sin los cuales no poseen ninguna razón de ser" ${ }^{25}$, se proponen a continuación determinadas medidas correctoras que se consideran convenientes para garantizar su adecuada protección:

- Protección legal. Teniendo en cuenta la situación legal en la que se encuentran las motillas y a fin de garantizar su protección se propone:

- La catalogación e inventario de todas las motillas que se conozcan y que carezcan de dicha protección por tratarse de localizaciones inéditas. A pesar de que en 2008

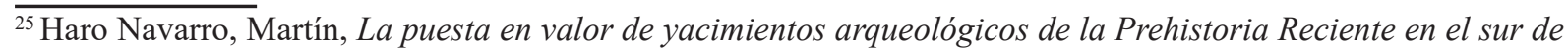
la Península Ibérica, tesis doctoral, Universidad de Granada, 2011, p. 520. «http://hdl.handle.net/10481/20198» [consultado el 10 de setiembre de 2017].
} 
se presentó a las administraciones competentes ${ }^{26}$ un inventario de motillas con localizaciones inéditas (para su declaración como Bien de Interés Cultural), dos años más tarde, con motivo de la consulta del catálogo para la realización de una prospección motivada por un proyecto subvencionado por la Junta de Comunidades de Castilla-La Mancha, se pudo comprobar que aún no figuraban inventariadas. Asimismo, en 2010 se presentaron los resultados de esa nueva prospección a las administraciones competentes (donde se incluyeron las medidas mínimas de protección a adoptar sobre el terreno) ${ }^{27}$, con una actualización de dicho inventario que incluía localizaciones inéditas para que fueran catalogadas e inventariadas, datos que un año más tarde se dieron a conocer en las V Jornadas de Investigación del Departamento de Prehistoria y Arqueología de la Universidad Autónoma de Madrid ${ }^{28}$. A este conjunto de localizaciones inéditas, presumiblemente ya inventariadas desde que se notificó su existencia, hay que sumarle la nueva localización de la Motilla de Mari López, mencionada con anterioridad.

- Inclusión de los yacimientos en los respectivos Catálogos del Plan de Ordenación Municipal, ya que los Ayuntamientos, según el artículo 7 de la Ley de Patrimonio Histórico Español, deben cooperar con los organismos competentes para la ejecución de esta Ley en la conservación y custodia del Patrimonio Histórico Español comprendido en su término municipal, adoptando las medidas oportunas para evitar su deterioro, pérdida o destrucción.

- A pesar de que en 2012 la Asociación Profesional de Arqueología y Patrimonio de Castilla-La Mancha solicitó formalmente la declaración de todas las motillas como Bien de Interés Cultural a la administración competente, hasta la fecha tan solo tres cuentan con esa protección (El Azuer, Los Palacios y El Acequión). Algunos investigadores han hecho eco de esta situación en otras publicaciones como Gonzalo Aranda Jimenez, para quien "[Las] motillas son un patrimonio muy frágil que debería tener el mayor grado de protección posible" ${ }^{29}$, o Luis Benítez de Lugo, quien considera que "[el Bien de Interés Cultural ] es la única categoría jurídica capaz de ofrecer protección" ${ }^{30}$. Insistimos nuevamente en su declaración como Bien de Interés Cultural, de acuerdo con la Ley 4/2013 de 16 de mayo de Patrimonio Cultural de Castilla-La Mancha, al ser consideradas como asentamientos no solo emblemáticos de la Edad del Bronce en La Mancha sino

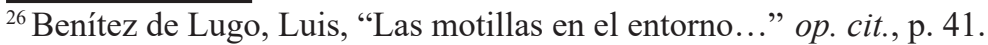

${ }^{27}$ Lenguazco González, Rebeca, Informe final prospección arqueológica del proyecto de investigación Ocupación del territorio y aprovechamiento de recursos en el Bronce de La Mancha: las motillas de la provincia de Ciudad Real y su territorio de explotación directa, memoria inédita presentada en la Dirección General de Patrimonio Cultural de Toledo, 2010.

${ }^{28}$ Lenguazco González, Rebeca, "Las Motillas de la Provincia de Ciudad Real", en Bar-Magen, Alexander et al. (coords.), Actas de las V Jornadas de Investigación del Departamento Prehistoria y Arqueología de la UAM, Madrid, Universidad Autónoma de Madrid, 2016, pp. 427-438.

${ }^{29}$ Mejías Moreno, Miguel et al., Arqueología, Hidrogeología ... op. cit., p. 9.

${ }^{30}$ Benítez de Lugo, Luis, "Las motillas en el entorno..." op. cit., p. 41.
} 
también únicos en la Prehistoria peninsular, lo que las convierte según la normativa vigente en yacimientos susceptibles de recibir la máxima protección arqueológica.

- Tareas de salvaguarda, entendiendo como tal cualquier medida de conservación que no implique intervención directa, es decir, medidas mínimas de protección como las que se proponen a continuación:

- Limpieza exhaustiva de cortes abiertos y estructuras arqueológicas para valorar los daños producidos sobre el conjunto tras su abandono, teniendo especial cuidado con la eliminación de la cobertura vegetal, ya que la extracción de las raíces afectaría tanto a las estructuras murarias como a los niveles arqueológicos.

- Tras la documentación fotográfica y planimétrica de los cortes abiertos se debería proceder a la cubrición con maya geotextil y capa de áridos o tierra vegetal de los restos estructurales emergentes y perfiles.

- Vallado integral de las parcelas que ocupan los distintos conjuntos arqueológicos a fin de evitar posibles expolios, destrozos o caídas accidentales, exceptuando aquellos asentamientos que se encuentran en zonas encharcadas en la actualidad, como las motillas de Las Cañas, Carrión y Cueva Morenilla, o las motillas del Espino o Los Palacios localizadas en parcelas actualmente valladas.

- Tareas de conservación y restauración. Las tareas de conservación y restauración en este tipo de yacimientos son bastante complejas, como se ha podido ver recientemente en las llevadas a cabo en la Motilla de El Azuer, debido a la gran acumulación sedimentaria, a la superposición de fases constructivas y a los problemas del estado de conservación de las estructuras murarias ${ }^{31}$. Las motillas que necesitan inminentemente actuaciones de restauración y conservación, para así evitar su constante deterioro que con el tiempo daría lugar a pérdidas irreparables, son aquellas en las que se han desarrollado excavaciones arqueológicas que han dejado visibles vestigios y perfiles estratigráficos de mayor entidad y riesgo de derrumbarse (motillas de Los Romeros, Los Palacios, Retamar y El Acequión, ya que el Azuer está consolidada, mientras que Las Cañas se localiza bajos las aguas de las Tablas de Daimiel y La Membrilleja ha sido totalmente desmantelada).

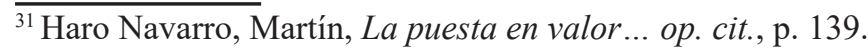




\section{Conclusiones}

Aunque todas las motillas presentan un estado de abandono que favorece su constante degradación, exceptuando el Azuer que es la única que ha sido restaurada y consolidada y en la que se desarrollan labores de acondicionamiento, limpieza y mantenimiento, se aprecian distintos estados de conservación según el método empleado, presentando la mayoría unas condiciones de conservación buenas o regulares frente al 35\% de los conjuntos arquitectónicos que presentan unas condiciones malas o muy malas.

Entre los factores de deterioro que afectan al estado de conservación de los asentamientos se encuentran los naturales, cuyos procesos geomorfológicos postdeposicionales más destacados son la erosión, transporte y sedimentación provocada por distintos factores como los medioambientales (lluvia, viento o cambios de temperatura); los geomorfológicos y geotécnicos o la propia gravedad; los biológicos (fauna y flora), que provocan derrumbes, descohesión, movimientos, fisuras y fracturas alterando estructuras murarías (sobre todo tapiales) y niveles arqueológicos; pero, sobre todo, van a ser los factores antrópicos los que más van a condicionar su estado de conservación. Entre los factores antrópicos documentados se encuentran: las excavaciones arqueológicas, que originan el debilitamiento de las estructuras arquitectónicas al ser exhumadas en las excavaciones si no se consolidan; la reocupación de un mismo espacio en épocas distintas, que acaba generando alteraciones en las estructuras murarias y en la propia estratigrafía; y las denominadas intervenciones "no arqueológicas" (las excavaciones ilícitas, la realización de obras públicas, el desarrollo urbanístico, la construcción de hornos de cal $\mathrm{y}$, fundamentalmente, la actividad agrícola), que provocan la destrucción parcial o total de estructuras murarias y niveles arqueológicos, afectando tanto a la interpretación del registro arqueológico como a la estabilidad del propio conjunto arquitectónico.

En este sentido, cabe destacar que el hecho de que la mayor parte de los asentamientos se encuentren en suelos dedicados a la explotación agrícola intensiva aumenta su vulnerabilidad, tal y como se ha podido valorar tras la consulta de las fotografías aéreas que nos han mostrado el constante y alarmante deterioro que han sufrido las motillas desde mediados del siglo pasado.

La estructura atumulada de algunos de los asentamientos es en la actualidad prácticamente imperceptible, quedando a simple vista escasos fragmentos cerámicos de dispersión sobre el terreno y su recuerdo de lo que fue plasmado en un fotograma, en el mejor de los casos. Pero esta situación no debe confundirse con la desaparición total de niveles arqueológicos ya que, aunque no se aprecien estructuras emergentes en la actualidad, pueden conservarse restos estructurales así como niveles arqueológicos en el subsuelo, máxime si tenemos en cuenta la localización de 
la mayor parte de los enclaves en zonas de inundación, pudiendo haberse colmatado los niveles inferiores de las fortificaciones y, en su caso, de los poblados circundantes, con sedimentos aportados por las aguas. En estos casos, la aplicación de la prospección geofísica ayudaría a detectar la existencia de restos arqueológicos en el subsuelo y la realización de algún sondeo arqueológico manual permitiría corroborar dichos datos y evaluar la potencia estratigráfica.

La preocupante situación, en cuanto al constante deterioro de unos asentamientos que, como hemos dicho con anterioridad, merecen toda nuestra atención no solo por ser emblemáticos del Bronce de La Mancha sino únicos en nuestra Prehistoria, nos obliga a proponer unas medidas que garanticen su adecuada protección. Desde el punto de vista legal, creemos conveniente, coincidiendo con otros investigadores que desde hace años llevan haciendo hincapié en esta situación, aumentar su grado de protección como Bien de Interés Cultural dentro de la categoría de Zona Arqueológica, con el que solo cuentan en la actualidad las motillas de El Azuer, Los Palacios y El Acequión.

Asimismo, diversas motillas requieren en la actualidad, debido a que presentan cortes estratigráficos abiertos y estructuras murarias visibles con abundante vegetación, una limpieza que permita valorar los daños producidos sobre el conjunto tras su abandono y, si procede, plantear medidas de restauración y conservación a fin de evitar su progresivo deterioro que con el tiempo daría lugar a pérdidas irreparables. Por último, sería deseable cubrir con maya geotextil y capa de áridos o tierra vegetal los restos estructurales emergentes y perfiles si no se pretende intervenir arqueológicamente a corto plazo.

Finalmente, queremos incidir en la necesidad de que todos los trabajos desarrollados deban ser debidamente publicados y divulgados, también los derivados del estudio de materiales o de intervenciones antiguas, para fomentar el interés y concienciar a la ciudadanía de la importancia de conservar y proteger este tipo de yacimientos. 